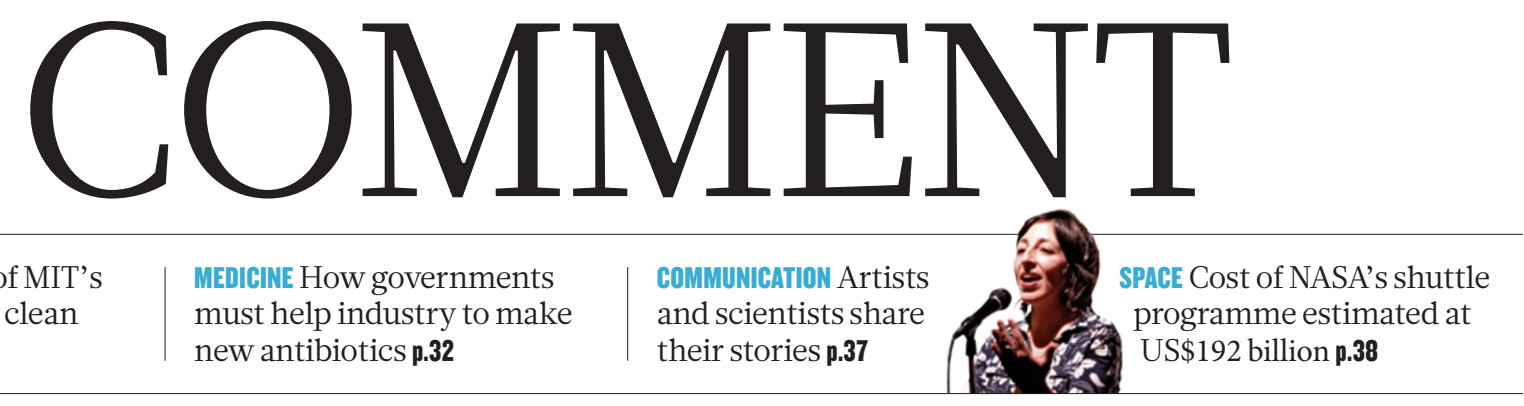

FUNDING The lessons of MIT's 150-year search for clean cash $\mathbf{p . 3 0}$ must help industry to make new antibiotics $\mathbf{p . 3 2}$ and scientists share their stories $\mathbf{p . 3 7}$

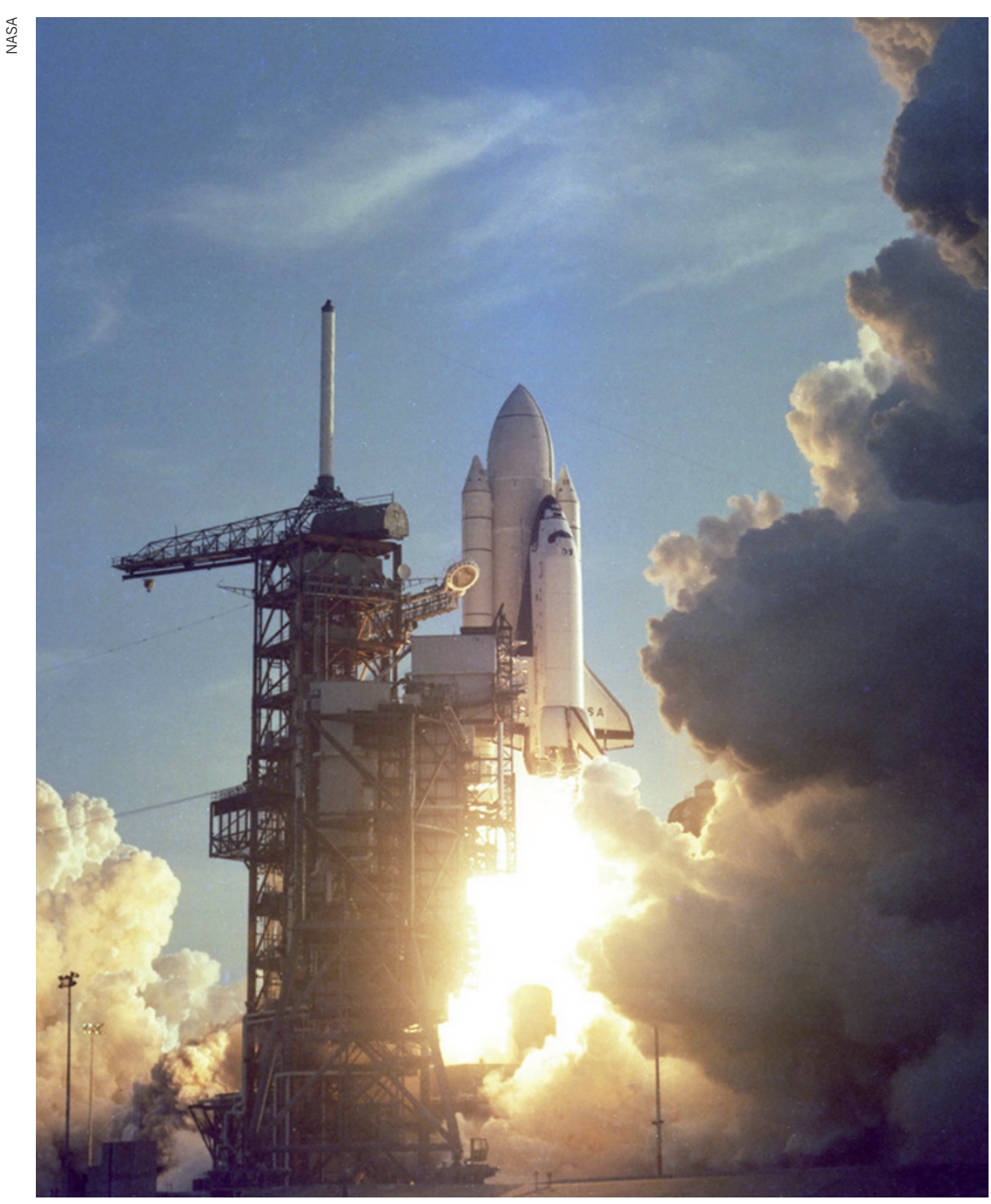

Launch of the first shuttle, Columbia, in 1981. Will NASA have a future to rival its past?

\section{NASA: what now?}

This month marks 50 years since Yuri Gagarin first ventured into space in the Vostok 1 mission, and 30 years since NASA's first shuttle flight. As the shuttle Endeavour prepares for its final flight, seven experts outline what NASA's priorities need to be.

\section{DENNIS BUSHNELL Revolutionize research}

\author{
Chief scientist at NASA Langley \\ Research Center
}

To achieve revolutionary goals, such as sending humans to explore the Solar System, NASA needs to develop revolutionary technologies. Because it is extremely difficult to pick winners in advance, research and development is required in several areas simultaneously.

Transporting humans to low-Earth orbit - such as the International Space Station and beyond are two very different missions. But they both depend on the same metrics: safety and cost.

Humans have been travelling to and from low-Earth orbit for some 50 years, mostly on what were once military rockets. Today's commercial rockets use similar expendable technologies. The development firm Space Exploration Technologies (SpaceX) in Hawthorne, California, achieved notable success last year with rocket launches at quite low cost. Thus, with due attention to safety, commercial transportation of humans to lowEarth orbit should be feasible.

Transport of humans outside low-Earth orbit, especially to the Moon, Mars and beyond, is a wholly different challenge. Aside from Apollo, which 'only' went to the Moon, we have almost no experience to draw on. Also, such expeditions become exceedingly costly with existing rocket technology if they are to guarantee that crew members will remain healthy during long missions.

Revolutionary technologies should be targeted at: reducing the mass of the vehicle; novel launch and propulsion systems (including alternative fuels, such as positrons, energy beaming and in-orbit refuelling); and intelligent architecture and systems for more affordable life-support and radiation protection. Several of these technologies could be truly game-changing. The use of nanotubes in spacecraft construction, for example, could reduce the 'dry mass' the amount to be launched, excluding 
$>$ fuel - by three to five times, if we can create structural materials with the same strength properties as individual nanotubes.

A final alternative to sending humans to the toxic environment of Mars would be to develop space exploration for everyone using immersive virtual reality and remote planetary sensors, with autonomous robotics to supply the data. This could offer a better-than-being-there experience at much reduced cost and risk.

MARC GARNEAU

\section{Get us to Mars}

\section{First Canadian in space and now a Member of Parliament}

I believe there is a specific challenge that can galvanize us all: sending humans to Mars. A clearly defined objective can seize the imagination. Neil Armstrong understood this when he criticized his country's decision to take a broader approach to space exploration rather than giving itself something with a specific end point, if not an end date.

Last year, President Barack Obama cancelled the Constellation programme intended to return astronauts to the Moon. As a result, the road map for human space exploration is no longer as clear as it was. NASA and other space agencies are about daring and inspiration. But while their engineers and scientists develop new technologies and make new discoveries, it is the public who must be mobilized to support human spaceflight. This happened with Apollo when there was a race to win, and money was no object then.

Today, there is no clear race to win and money is very much a limiting factor - but that doesn't mean there is no reason to once again attempt what seems impossible. For me, that should be an international human mission to Mars led by the United States. With the completion of the International Space Station, we have proved that many countries can work together and share both the cost and the development of new technologies.

\section{JOHN M. LOGSDON \\ Build a case for humans in space}

\author{
Professor emeritus at George \\ Washington University
}

NASA will probably continue to muddle along once the shuttle retires. Over the past 20 years the United States has spent more than $\$ 20$ billion on developing an alternative way to take humans into space. None even reached

the flight-test stage. The 2003 Columbia Accident Investigation Board Report (of which I was an author) called the lack of a replacement for the shuttle "a failure of national leadership". That failure continues.

Eight years later, there is still no replacement in sight, just the hope that together, the private sector and NASA can develop ways to carry astronauts to the International Space Station (ISS) and replace NASA's embarrassing dependence on Russian rockets. Since the Columbia accident, NASA has used expendable vehicles to launch its science missions, so the end of the shuttle programme will have little impact on space science.

The biggest uncertainty is whether the United States will even have a human-spaceflight programme once the ISS is retired in 2020. In 2009, the Augustine Commission called for a spaceflight programme that is "worthy of a great nation". In the commission's view, that meant human exploration at increasingly greater distances from Earth. Since then, there has been a confused and confusing debate among the White House, US Congress, NASA and the non-government space community over the best way to get started. No compelling proposal has emerged. The case has not yet been made for going back to the Moon, visiting a nearEarth asteroid or sending humans to Mars. Until it is, the US leadership is unlikely to commit the country to human spaceflight "worthy of a great nation".

\section{ROALDSAGDEEV Send more robots} Former director of the Russian Space
Research Institute and adviser to
former President Mikhail Gorbachev

The closing down of NASA's space-shuttle programme leaves the Russian Soyuz rockets as the only spacecraft capable of delivering manned vehicles to the International Space Station (ISS). With the right political will, however, there is no reason why NASA cannot regain self-sufficiency in the next few years, even on a more modest budget.

In the interim, NASA has a genuine historic opportunity to rethink its goals once the ISS discontinues operations. An earlier vision to return astronauts to the Moon is off the agenda of the administration of President Barack Obama (and perhaps for the foreseeable future). A mission to Mars, a dream of spaceflight pioneers, in an environment of global multidimensional (not simply economic) crisis, will probably remain a dream for decades to come.

At the same time, the unmanned space programme is developing with tremendous success and is costing much less. Robotic missions have vastly enriched our knowledge of the Solar System, and of Earth in particular, and have put numerous new-generation telescopes into space. These developments challenge the need for a costly human presence in space. Yes, astronomers are thankful to NASA's shuttle astronauts for prolonging the life of the Hubble telescope, thereby making it so successful. And in its last flight on 19 April, the Endeavour shuttle will deliver to the ISS an alpha-magnetic spectrometer the most advanced high-energy experiment yet to be deployed in space.

But if such ventures remain isolated episodes, the expensive game of human spaceflight risks degenerating into 'space tourism' paid for by taxpayers.

\section{ED LU \\ Deflect risky asteroids}

\section{Physicist, entrepreneur and former shuttle astronaut}

The reason for human spaceflight is to protect human civilization. That means preventing direct threats such as asteroid impacts on Earth, as well as opening up the Solar System to human activity, including commerce, science, exploration and, some day, settlement.

NASA should survey and catalogue the orbits of potentially threatening asteroids, and show that humans can alter the Solar System (if ever so slightly) by deflecting a non-threatening asteroid using a robotic spacecraft. Such a focus would tie together the human-spaceflight programme with the robotic planetary-exploration programme in a common purpose.

Most importantly, NASA must move faster. The agency moved so slowly on some recent major programmes that they have been cancelled for lack of progress. Its plans for a heavy-lift rocket should therefore also be scrapped: it is too expensive, and meaningful progress will not be made until the 2020s.

Instead, NASA should find ways to solve the fuel problem: the fact that most of the mass of any spacecraft leaving Earth is taken up by fuel. NASA should develop a fuel depot in low-Earth orbit that can be used to refuel missions to deep space. Commercial firms could be paid to deliver fuel to the depot. Routine operations of this sort will bring down the overall costs and free NASA up to develop its deep-space missions. The agency would then be able to make progress in extending the reach of humanity into the Solar System.

The author declares competing financial interests: details accompany the full-text HTML version of the paper at go.nature.com/wx4vlv. 

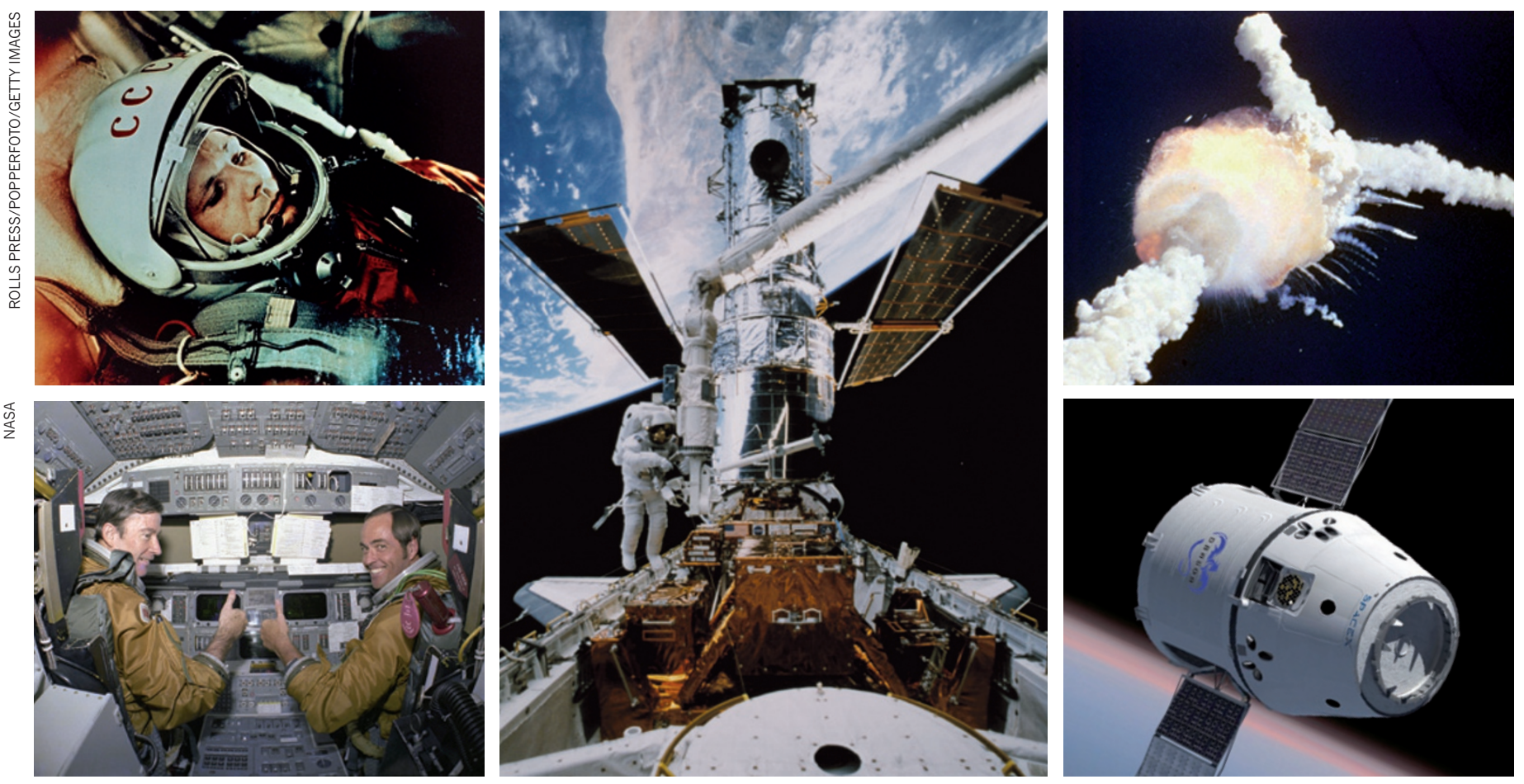

The highs and lows of human spaceflight. In 1961, Yuri Gagarin was the first man in space (top left). The shuttle first took flight 30 years ago (bottom left).

Shuttle astronauts helped repair the Hubble Space Telescope in the 1990s (middle). The Columbia shuttle exploded after launch in 2003 (top right). Last year, a private company successfully launched a reusable space capsule (bottom right).

\section{MATT MOUNTAIN Find a united purpose}

\section{Director of NASA's Space Telescope Science Institute and scientist at the James Webb Space Telescope}

Human spaceflight will be at its best when NASA can demonstrate that the whole is greater than the sum of its individual parts.

In the 1990s, NASA's ambitious shuttle missions to repair and upgrade the Hubble Space Telescope ensured that Hubble remained the most scientifically productive telescope in history, and uniquely captured the public's imagination. What stood these missions apart from other NASA humanspaceflight activities was that the whole agency was committed to a coherent purpose - a partnership between science and human spaceflight to explore the Universe - something that only NASA has done.

Now imagine a NASA committed to lead an international spaceflight endeavour to search for habitable worlds, and to extend humanity's reach to Mars and beyond - I suspect there would be a collective sigh of relief among the world's space agencies. It would give immediate focus and relevance to the International Space Station as a platform for understanding how to sustain a long-term human presence in space. For Mars, the focus should be not on rockets that hark back to the Apollo era - but on developing truly novel propulsion systems that allow humans to explore the entire Solar System.

In the medium term, NASA's astronauts could help to assemble and service giant space telescopes capable of searching for life around another star. The discovery of extra-terrestrial life would have as profound an impact on the twenty-first century as Neil Armstrong's Moon walk had on the twentieth.

\section{NEAL STEPHENSON Ditch the rockets}

\section{Science-fiction author and space enthusiast}

NASA should throw itself into developing radically cheaper ways of getting into space: a task that only it can do, and that would help to restore the lustre and esprit de corps of a legendary organization.

Rockets got as good as they are ever going to get four decades ago. Measured in terms of specific impulse - the momentum imparted to the vehicle per unit of fuel, and the only factor that matters as far as the laws of physics are concerned - no game-changing advances have been made since the Apollo programme. The technologies pioneered by the Soviet Union and the United States have been endlessly cannibalized by NASA and parroted by many other countries.

The only way to fundamentally change humanity's relationship with space is to develop radically new launch systems, a challenge that no private company is likely to undertake. This is a job for NASA if ever there was one. The only catch is that it has to be NASA at its best - the NASA that many of us idolized in our youth - and not the grab-bag of aerospace-industry support programmes that the agency has become in the decades since the last Moon landings.

Scientists and engineers have been proposing alternative launch technologies since the 1950s, including laser- and microwavepowered propulsion, large gun-like devices, orbital tethers, space elevators, airplane- and balloon-assisted mechanisms and scramjets. None of these has taken hold, not because they are crazy (although some might be) but because the unbelievable amounts of taxpayers' money collected during the cold war and ploughed into old-school launch systems gave rockets a technological lead, and a privileged legal, regulatory and political position, unassailable by mere free enterprise.

Budget shortfalls provide an opportunity for NASA to eliminate many programmes that in happier economic times would be politically untouchable. NASA should make the most of this opportunity, and then rededicate itself to striving for the sorts of radical advances that, 50 years ago, had the power to awe the world. 
g

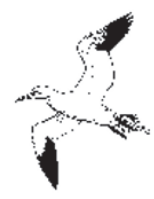

1948

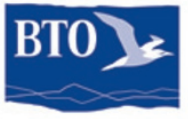

2002

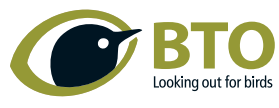

2010 h

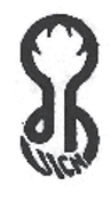

1954

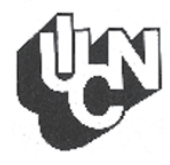

1977

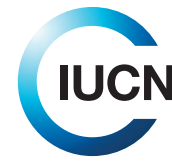

2008 i

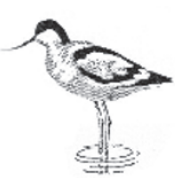

1966

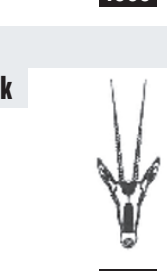

1950

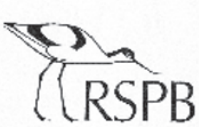

1975

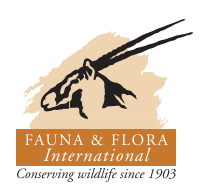

1994

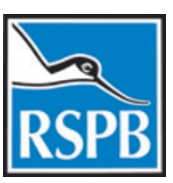

1987 j
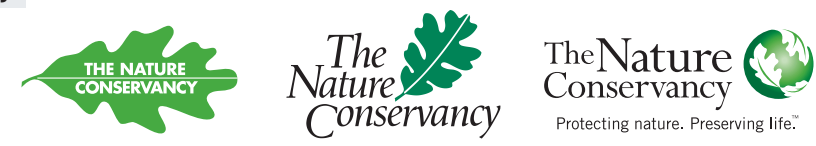

$\lcm{1960}$

1987
I

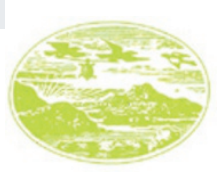

1961

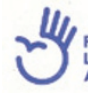

Friends of the Earth Les Amis de la Terre
Amigos de la Tierra

FAUNA \& FLORA

2010

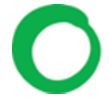

Friends of the Earth International 2001
The IUCN, for example, has never sought a fluffy image. This is partly because that public appeal was provided by the WWF, which was founded to raise funds for the cash-strapped union. It is also because a hefty chunk of the IUCN's revenue is clinched in diplomatic dealings, which might explain why, after the extinction of the 'flaming artichoke', the union was content to spend several decades tinkering with various permutations of its acronym. Finally, in 2008, the IUCN (with advice this time from New York advertising agency Young and Rubicam) settled for a blue ring encircling the organization's initials. "The blue ' $\mathrm{C}$ ' of the logo represents the planet and the union," says John Kidd, the IUCN's head of global communications. "The IUCN works on complex issues, often with complex solutions, but the logo is clean, clear, simple and, over time, hopefully memorable."

\section{GLOBAL APPEAL}

With the emergence of a truly global culture, and global concerns such as acid rain, nuclear fallout and climate change, it makes sense that this kind of holistic, planetary design has become more common. Most of the Friends of the Earth network swapped the charity's abstract sun and hand for a bright green, marker-pen circle in 2001. "It is a very simple design, and the idea was to represent the Earth, sustainability, cycles and unity," says Ann Doherty, communications coordinator at FOE International.

Similarly, in 2007, the international environmental organization the Nature Conservancy wrapped its trademark oak leaves around a green sphere (Fig. 1j). "As we've expanded outside the United States, now to more than 30 countries, we've incorporated the round, globe-like symbol to represent our focus on protecting lands and waters around the world," says Valerie Dorian, director of brand marketing and strategic partnerships. Even more nationally focused outfits, such as the United Kingdom's Woodland Trust, have adopted circular or spherical designs that give a nod to the scale of the problem (see Fig. 1f).

Many of these trends - the abstraction, a human presence, the appearance of a global element - have come together in Conservation International's new brand. Part of the reason for axing the long-standing rainforest logo was that it did not reproduce well in miniature, a quality essential in today's relentlessly digital world. It also failed to reflect the breadth of the organization's twenty-first-century mission "to empower societies to responsibly and sustainably care for nature for the well-being of humanity"6. In other words, Conservation International is about more than just rainforests.

The logo was the result of a consultation with New York design agency Chermayeff \& Geysmar. "What Conservation International needed was not a literal picture that illustrates every single area of their activities, but rather a new, suggestive, and potentially expansive mark," says Sagi Haviv, the agency's principal designer. His solution - a blue circle underlined in green - is supposed to represent "our blue planet, emphasized, supported and sustained"; it also evokes an abstract human figure into the bargain.

The WWF's symbol is the most obvious exception that proves this trend towards global imagery. The organization never got type-cast in a species specific role; this is probably because the Chinese Cultural Revolution prevented the WWF from becoming involved with pandas until 1980. By then its panda had become established as a symbol with a truly global appeal.

So what should we make of a journey that began with literal, fine-art creations and has reached abstract images that make only a passing reference to nature? The answer, like the logos we're left with, is pretty simple. Conservation is no longer just about a single species on the brink of extinction, the habitat it's found in or some wider ecosystem. Now it's about the future of the planet. That, of course, means it's really all about us. $\triangle$ SEEBOOK REVIEW P. 290

Henry Nicholls is a science writer based in London. His latest book is The Way Of The Panda (Profile, 2010).

e-mail:henry@henrynicholls.com

1. Bonner, R. At the Hand of Man: Peril and Hope for Africa's Wildlife (Simon \& Schuster, 1993).

2. 'This is the symbol of the World Wildlife Fund.' Max Nicholson Archive, Linnean Society of London, EMN 8/7.

3. Oryx 24, 118-119 (1990)

4. Hughes-Evans, D. \& Aldrich, J. L. The Environmentalist 1, 91-93 (1981).

5. Schwarzenbach, A. Saving the World's Wildlife: WWF's First Fifty Years (Profile Books, 2011).

6. New Logo for a New Mission - Conservation International. (2010); available at http:// go.nature.com/us6yap

\section{CORRECTION}

In the Comment article 'NASA: what now?' (Nature 472, 27-29; 2011), the picture of the space shuttle Challenger disaster in 1986 was wrongly identified as that of Columbia in 2003. 